Article

\title{
Preparation of crown ether complexing highly active double metal cyanide catalysts and copolymerization of $\mathrm{CO}_{2}$ and propylene oxide
}

\author{
Min Zhang a,*,†, Yong Yang b,c,t, Liban Chen ${ }^{\mathrm{b}}$ \\ a College of Food and Horticultural Sciences, Foshan University, Foshan 528231, Guangdong, China \\ b Guangzhou Institute of Chemistry, Chinese Academy of Sciences, Guangzhou 510650, Guangdong, China \\ c University of Chinese Academy of Sciences, Beijing 100049, China
}

\section{A R T I C L E I N F O}

Article history:

Received 1 February 2015

Accepted 23 April 2015

Published 20 August 2015

Keywords:

Double metal cyanide

Carbon dioxide

Propylene oxide

Copolymerization

Crown ether

\begin{abstract}
A B S T R A C T
Double metal cyanide (DMC) catalysts are generally prepared by coprecipitation of potassium hexacyanocobaltate(III) with zinc chloride followed by complexation with tert-butanol, and these materials have been used for several decades in the copolymerization of $\mathrm{CO}_{2}$ and epoxides. However, the catalytic efficiency of DMC catalysts can be adversely affected by the presence of excess $\mathrm{K}^{+}$, and the preparation of these catalysts can therefore become complicated and time-consuming because of the multiple washing and centrifugation stages required for the removal of the excess $\mathrm{K}^{+}$. In this study, 18-crown-6 ether was used as an effective co-complexing agent for the removal of $\mathrm{K}^{+}$. A series of DMCs containing 18-crown-6 were prepared with different quantities of the crown ether and different washing times. The resulting crown ether-complexing catalysts (CDMCs) and DMC catalysts without crown ether were characterized by Fourier transform infrared spectroscopy, scanning electron microscopy, thermogravimetric analysis-IR and X-ray diffraction. These characterization results showed that the inclusion of 18-crown- 6 allowed for the formation of uniform and highly dispersed CDMC catalysts. In contrast, the DMC catalysts prepared in the absence of 18-crown-6 became uneven and delaminated during the purification by centrifugation, with high- and low-density portions of the material forming on the bottom and top of the catalyst cakes, respectively. The inclusion of 18-crown- 6 not only trapped $\mathrm{K}^{+}$but also participated in the complexion process. The complexion of tert-BuOH and 18-crown-6 led to a less crystalline form of the CDMC catalyst. Elemental analysis revealed that CDMC1 contained $1.2 \% \mathrm{~K}^{+}$. The copolymer was obtained by the copolymerization of $\mathrm{CO}_{2}$ with propylene oxide using $\mathrm{CDMC} 3$ catalyst, which was superior to the copolymer prepared using DMC1. CDMC3 was as active as DMC2 prepared without the crown ether but with seven washing steps. A hypothetical two-stage catalytic mechanism was proposed.
\end{abstract}

(C) 2015, Dalian Institute of Chemical Physics, Chinese Academy of Sciences. Published by Elsevier B.V. All rights reserved.

\section{Introduction}

$\mathrm{CO}_{2}$, which is widely known as one of the main greenhouse gases, could potentially be used as building block for the con- struction of useful aliphatic polycarbonates. Aliphatic polycarbonates are becoming increasingly important because of their extensive range of applications in the production of polyurethanes, coating materials, biodegradable surfactants and bio-

\footnotetext{
* Corresponding author. Tel/Fax: +86-757-85505064; E-mail: zhangmin@gic.ac.cn

$\dagger$ Min Zhang and Yong Yang contributed equally to this work.

This work was supported by the National Natural Science Foundation of China (20274053), the Natural Science Foundation of Guangdong Province (9151065004000005), and the Scientific and Technical Foundation of Foshan (2014GA000425, 2014AG10007).

DOI: 10.1016/S1872-2067(15)60868-3 | http://www.sciencedirect.com/science/journal/18722067 | Chin. J. Catal., Vol. 36, No. 8, August 2015
} 
medical materials $[1,2]$. Aliphatic polycarbonates are mainly prepared by transesterification [3] and $\mathrm{CO}_{2}$ coupling [4] reactions. A wide variety of catalytic systems have been developed during the last three decades for the efficient copolymerization of $\mathrm{CO}_{2}$ with epoxides, including $\mathrm{ZnEt}_{2}$-protic compounds [5,6], zinc glutarate or adipate [7-9], rare-earth catalysts [10-12], metal-porphyrins [13-15], zinc bis( $\beta$-diiminates) [16-18], salen-metal systems, metal microporous polymers [19-25] and double metal cyanide (DMC) catalysts [26-37]. DMC catalysts in particular have promising industrial prospects because of their high activity, cost-effectiveness and insensitivity to moisture.

DMC catalysts were initially used in the production of polyether and later utilized in the copolymerization of propylene oxide with $\mathrm{CO}_{2}$ [24-30]. DMC catalysts are typically prepared via a precipitation process with a heavy organic complexing agent such as tert-butyl alcohol ( $t$-BuOH), followed by multiple washing and centrifugation stages to allow for the removal of the excess potassium ions [26-29], which can have an adverse impact on the copolymerization of $\mathrm{CO}_{2}$ and propylene oxide [29]. A new process was recently developed to avoid the production of $\mathrm{K}^{+}$where $\mathrm{H}_{3} \mathrm{Co}(\mathrm{CN})_{6}$ was prepared according to an ion exchange method using $\mathrm{K}_{3} \mathrm{Co}(\mathrm{CN})_{6}$, followed by precipitation with $\mathrm{ZnCl}_{2}$ in methanol to give $[\mathrm{ZnCl}]^{+}\left[\mathrm{HCo}(\mathrm{CN})_{6}\right]^{2-}$ without any $\mathrm{K}^{+}$[29]. This material was subsequently used in the copolymerization of $\mathrm{CO}_{2}$ with propylene oxide to give a copolymer product with a high molar fraction of $\mathrm{CO}_{2}$ (about 60\%). Sebastian et al. [30] prepared a series of Zn-Co DMC catalysts with $\mathrm{K}^{+}$contents in the range of $0.41 \%-2.0 \%$ without the inclusion of an additional washing step. However, the highest catalytic efficiency achieved with these Zn-Co DMC catalysts for the copolymerization of $\mathrm{CO}_{2}$ and cyclohexene oxide was only $52.8 \mathrm{~g}$ polymer/g catalyst. In light of the problems posed by the presence of $\mathrm{K}^{+}$in these catalysts, significant research efforts have been directed towards the development of new techniques for the removal of free potassium ions from heterogeneous DMC catalysts. However, the traditional methods for the preparation of DMC catalysts require multiple washing and centrifugation (up to seven times), making these processes time consuming, inefficient and poorly reproducible [26-28,31,32].

It is noteworthy that 18-crown-6 ether has an appropriate hole size $(0.26-0.32 \mathrm{~nm})$ for the binding of $\mathrm{K}^{+}(0.266 \mathrm{~nm})$. Herein, we describe the results of our study towards the preparation of DMC catalysts in the presence of 18-crown- 6 with the aim of simplifying the washing and centrifugation steps. The resulting crown ether complexing $\mathrm{Zn}$-Co DMC catalysts were subsequently evaluated as catalysts for the copolymerization of $\mathrm{CO}_{2}$ with propylene oxide.

\section{Experimental}

\subsection{Materials}

Potassium hexacyanocobaltate(III), 18-crown-6, zinc chloride and tert-butyl alcohol were purchased as the analytical grade from Aladdin Reagent (Shanghai, China) and used without further purification. Propylene oxide was refluxed over calcium hydride and then stored over $3 \AA \AA$ molecular sieves prior to being used in the copolymerization reactions. $\mathrm{CO}_{2}(>99.9 \%)$ was purchased from Kedi Air Chmical (Foshan, China) and used without further purification.

\subsection{Preparation of the catalysts}

The methods used for the preparation of the catalysts are summarized in Table 1. CDMC1 was prepared according to Ref. [28,32] with minor modifications. Briefly, a solution of $\mathrm{K}_{3}\left[\mathrm{Co}(\mathrm{CN})_{6}\right]$ (1.66 g, $5 \mathrm{mmol}$ ) in distilled $\mathrm{H}_{2} \mathrm{O}(25 \mathrm{~mL})$ was added in a dropwise manner to a vigorously stirred suspension of $\mathrm{ZnCl}_{2}(2.5 \mathrm{~g}, 18.4 \mathrm{mmol})$ in a mixture of distilled $\mathrm{H}_{2} \mathrm{O}(75 \mathrm{~mL})$ and $t$-BuOH $(40 \mathrm{~mL})$ at $45{ }^{\circ} \mathrm{C}$ over $30 \mathrm{~min}$, and the resulting mixture was stirred for $2 \mathrm{~h}$. 18-Crown-6 (8 g, $30.3 \mathrm{mmol}$ ) was then added to the reaction in a single portion, and the resulting mixture was stirred for $3 \mathrm{~h}$ to allow for the complete complexation of the $\mathrm{K}^{+}$ions. The resulting white precipitate was isolated by centrifugation $\left(25^{\circ} \mathrm{C}, 15 \mathrm{~min}\right)$, suspended in $t$-BuOH $(140$ $\mathrm{ml}$ ) and stirred for $2 \mathrm{~h}$ at $45^{\circ} \mathrm{C}$. The mixture was then purified by centrifugation $\left(25^{\circ} \mathrm{C}, 15 \mathrm{~min}\right)$ to give the catalyst, which was dried under vacuum at $50{ }^{\circ} \mathrm{C}$ to constant weight, resulting in a cake. The top and bottom portions of the CDMC1 cake were labeled as CDMC1-T and CDMC1-B, respectively. All of the other catalysts prepared were defined in a similar manner. Elemental analysis of CDMC1 revealed $21.6 \% \mathrm{Zn}, 8.1 \%$ Co and $1.2 \% \mathrm{~K}$.

CDMC2 and CDMC3 were prepared according to a procedure similar to CDMC1 but with different crown ethers and washing times with a $1: 1(\mathrm{v} / \mathrm{v})$ mixture of $t-\mathrm{BuOH}$ and water.

DMC1 and DMC2 were synthesized according to a similar procedure to that used for CDMC 1 but without addition of the crown ether $[28,32]$. In the case of DMC2, the remaining $\mathrm{K}^{+}$ions were removed by washing the precipitate seven times with a mixture of distilled $\mathrm{H}_{2} \mathrm{O}$ and $t-\mathrm{BuOH}$ whilst decreasing the quantity of $\mathrm{H}_{2} \mathrm{O}$ and increasing the amount of $t$-BuOH. Elemental analyses revealed the following results: DMC1 (Zn $25.14 \%$, Co 8.53\%, K 1.43\%); DMC2 (Zn 30.85\%, Co 9.81\%, no $\mathrm{K}^{+}$ions were detected). DMC0 consisted of pure $\mathrm{Zn}_{3}\left[\mathrm{Co}(\mathrm{CN})_{6}\right]_{2}$, which was prepared in the absence of a complexing agent.

\subsection{Catalyst characterization}

Fourier transform infrared spectra (FTIR) were measured on an Analect RFX-65A FTIR spectrophotometer (Analect, USA). The surface morphologies of the DMC catalysts were

Table 1

Conditions used for the preparation of the different DMC catalysts a.

\begin{tabular}{lcc}
\hline Catalyst & Times of washing & Crown ether: $\mathrm{K}^{+}$molar ratio \\
\hline CDMC1 & 1 & 2 \\
CDMC2 & 1 & 1 \\
CDMC3 & 2 & 2 \\
DMC0 & 1 & 0 \\
DMC1 & 1 & 0 \\
DMC2 & 7 & 0 \\
\hline
\end{tabular}

${ }^{a} \mathrm{~K}_{3}\left[\mathrm{Co}(\mathrm{CN})_{6}\right](1.66 \mathrm{~g})$ was used at $45^{\circ} \mathrm{C} . \mathrm{ZnCl}_{2}(2.5 \mathrm{~g})$ was used in CDMC1, CDMC2, CDMC3, DMC1 and DMC2 catalysts. A smaller amount of $\mathrm{ZnCl}_{2}$ (1.02 g) was used in DMC0. 
observed by scanning electron microscopy (SEM) on a JSM-6360LV scanning electron microscope (JEOL, Japan). Prior to scanning, the top and bottom portions of the DMC and CDMC cakes were coated with a thin layer of gold under high vacuum conditions. X-ray powder diffraction (XRD) patterns were collected on a Bruker D8 Advance diffractometer (Bruker, Sweden) using monochromated radiation. The chemical compositions of the catalysts were obtained by elemental analysis using a Vario EL CHNS elemental analyzer (Elementar, Germany) equipped with a PE5100 ICP-AES instrument (Perkin Elmer, USA). A Thermogravimetric analysis/infrared spectra (TGA-IR) were recorded on a TG-209/Vector ${ }^{\mathrm{TM}}-22$ system (Netzsch, Germany). ${ }^{1} \mathrm{H}$-NMR spectra of the copolymers were recorded on a DRX-400 spectrometer (400 MHz) using $\mathrm{CDCl}_{3}$ as a solvent. The molecular weights and molecular weight distributions of the copolymers were determined by gel permeation chromatography using tetrahydrofuran as a solvent with on a Waters 515-410 system (Waters, USA).

\subsection{Copolymerization of $\mathrm{CO}_{2}$ and propylene oxide}

Several copolymerization experiments were conducted in a $130 \mathrm{~mL}$ autoclave to evaluate the catalytic performance of the catalysts. The autoclave was loaded with a catalyst, placed under vacuum at $25{ }^{\circ} \mathrm{C}$ and purged with $\mathrm{N}_{2}$ three times to allow for the removal of any moisture. The autoclave was then cooled to room temperature and charged with propylene oxide using a syringe before being pressurized with $\mathrm{CO}_{2}$ to the desired pressure. Upon completion of the reaction, the autoclave was cooled to room temperature and the $\mathrm{CO}_{2}$ released.

\section{Results and discussion}

\subsection{FT-IR spectra}

The $\mathrm{C} \equiv \mathrm{N}$ groups in the FTIR spectra of Zn-Co DMC catalysts generally give strong stretching vibrations $\left(v_{\mathrm{C}=\mathrm{N}}\right)$ around $2196 \mathrm{~cm}^{-1}$ following the coordination of $t-\mathrm{BuOH}$, whereas the corresponding $v_{\mathrm{C}} \equiv \mathrm{N}$ value of pure $\mathrm{Zn}_{3}\left[\mathrm{Co}(\mathrm{CN})_{6}\right]_{2}$ is $2185 \mathrm{~cm}^{-1}$ [32]. As shown in Fig. 1, the FTIR spectra of CDMC1 and CDMC3 still contained a peak at $2195 \mathrm{~cm}^{-1}$ following the addition of

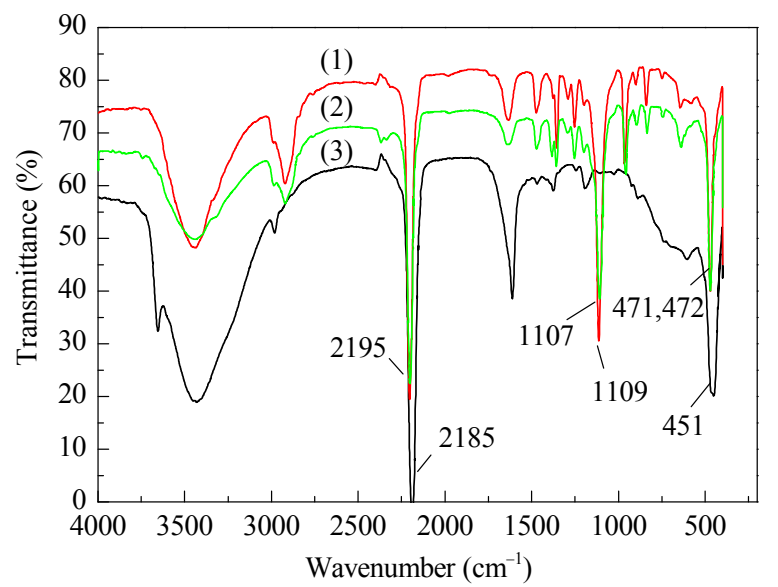

Fig. 1. FTIR spectra of CDMC1 (1), CDMC3 (2) and DMC0 (3). 18-crown-6. Structural transformations of this type are generally thought to originate from the effective coordination of $\mathrm{Zn}$ with $\mathrm{O}$ for the polymerization process. Notably, the stretching vibration of the $\mathrm{Co}-\mathrm{C}$ bond in pure $\mathrm{Zn}_{3}\left[\mathrm{Co}(\mathrm{CN})_{6}\right]_{2}$ (DMCO), which is generally observed at $451 \mathrm{~cm}^{-1}$, was appeared at 471 and $472 \mathrm{~cm}^{-1}$ in CDMC1 and CDMC3, respectively. Furthermore, the peaks at 1107 and $1109 \mathrm{~cm}^{-1}$ in CDMC1 and CDMC3 were attributed to the stretching vibrations of the $\mathrm{C}-\mathrm{O}-\mathrm{C}$ bonds of 18-crown-6. Although different amounts of 18-crown-6 were added to CDMC1 and CDMC3, the IR curves of these materials were almost identical except for minor differences in the stretching vibrations of the $\mathrm{C}-\mathrm{O}-\mathrm{C}$ and $\mathrm{Co}-\mathrm{C}$ bonds.

The FTIR data for the stretching vibrations of the $\mathrm{C} \equiv \mathrm{N}, \mathrm{Co}-\mathrm{C}$ and $\mathrm{C}-\mathrm{O}-\mathrm{C}$ bonds of the $\mathrm{CDMC}$ and DMC catalysts are shown in Table 2. These results revealed that the FTIR spectra of the top and bottom surfaces of CDMC1 and CDMC3 cakes, which were prepared with a crown ether to $\mathrm{K}^{+}$molar ratio of $2: 1$, were the same. This indicated that the cakes of the CDMC1 and CDMC2 materials were totally uniform in terms of their composition. In contrast, the FTIR spectra of the top and bottom surfaces of the DMC1 and DMC2 cakes, which were prepared without any crown ether, revealed that the peaks corresponding to the stretching vibrations of the $\mathrm{C} \equiv \mathrm{N}$ bonds were different, which indicated that the materials were unevenly distributed in terms of their composition. Polymers containing ether groups [e.g., poly(tetramethylene ether glycol) and polyethylene glycol] can be used as complexing agents to improve the activity of DMC catalysts [32,33]. For the CDMC catalysts, it was envisaged that the addition of 18-crown- 6 would not only lead to the binding of the $\mathrm{K}^{+}$but that it would also coordinate $\mathrm{Zn}^{2+}$. In this way, the 18-crown-6 could perform as a co-complexing agent, which could improve the homogeneity of the catalysts. FTIR analysis of CDMC3 revealed stretching vibrations for the $\mathrm{C}-\mathrm{O}-\mathrm{C}$ bonds of the 18-crown- 6 at $1107 \mathrm{~cm}^{-1}$, whereas the corresponding band appeared at $1109 \mathrm{~cm}^{-1}$ in CDMC1. This result therefore illustrates the differences in the complexation states of the different catalysts. In fact, the stretching vibrations of the Co-C bonds in all of the catalysts prepared in the current study except for DMC0 were in the range of 471-472 $\mathrm{cm}^{-1}$. The similarity in these values could be attributed to the Co-C bonds being positioned inside of the molecules so that they would not be affected by changes in the chemical environment. In summary, these results show that the addition of 18-crown-6 led to significant improvements in the homogeneity of catalysts.

Table 2

IR wavenumber data of $\nu_{\mathrm{C} \equiv \mathrm{N}}, \nu_{\mathrm{Co}-\mathrm{C}}$ and $\nu_{\mathrm{C}-\mathrm{O}-\mathrm{C}}$ in Zn-Co DMC catalysts.

\begin{tabular}{lccc}
\hline Catalyst & $\nu_{\mathrm{C}=\mathrm{N}}\left(\mathrm{cm}^{-1}\right)$ & $\nu_{\mathrm{Co}-\mathrm{C}}\left(\mathrm{cm}^{-1}\right)$ & $\nu_{\mathrm{C}-\mathrm{O}-\mathrm{C}}\left(\mathrm{cm}^{-1}\right)$ \\
\hline CDMC1-T & 2195 & 471 & 1109 \\
CDMC1-B & 2195 & 471 & 1109 \\
CDMC2-T & 2195 & 471 & 1109 \\
CDMC2-B & 2195 & 471 & 1109 \\
CDMC3-T & 2195 & 472 & 1107 \\
CDMC3-B & 2195 & 472 & 1107 \\
DMC1-T & 2197 & 472 & - \\
DMC1-B & 2195 & 472 & - \\
DMC2-T & 2197 & 472 & - \\
DMC2-B & 2195 & 472 & - \\
DMC0 & 2185 & 451 & - \\
\hline
\end{tabular}



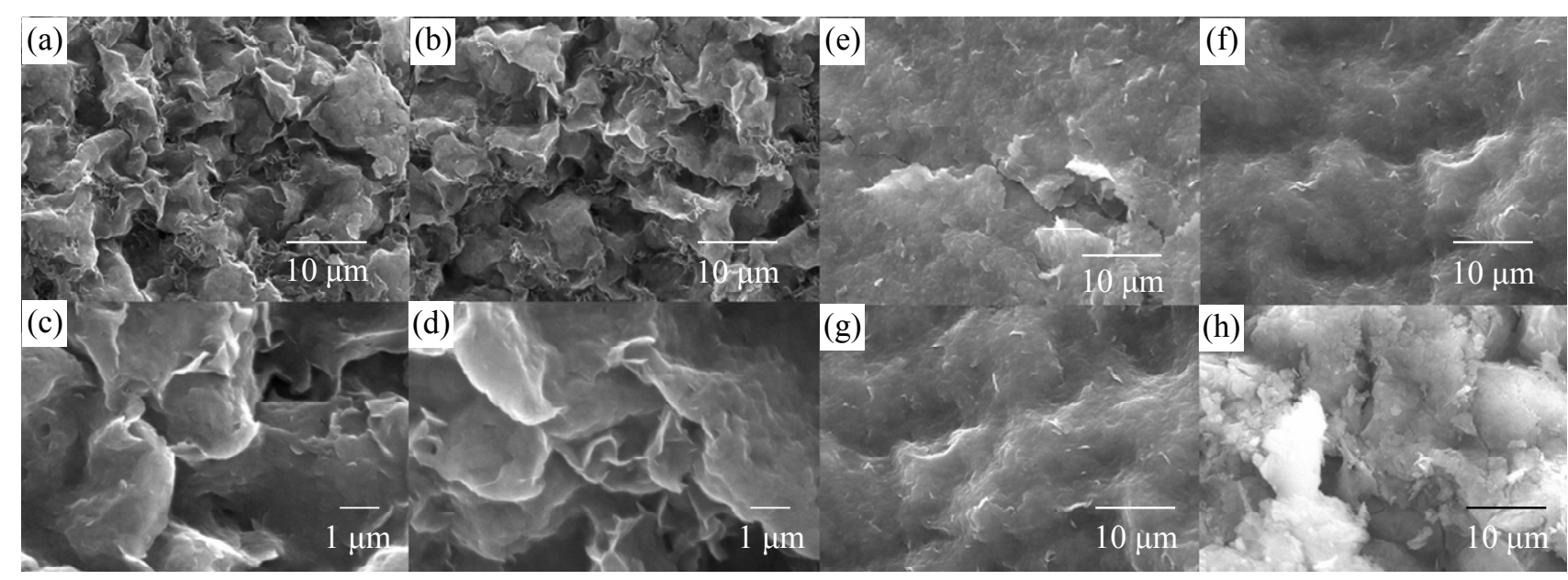

Fig. 2. SEM images of CDMC3-T (a), CDMC3-B (b), CDMC3-T (c), CDMC3-B (d), DMC1-T (e), DMC1-B (f), DMC2-T (g) and DMC2-B (h).

\subsection{SEM results}

The surface morphologies of the different catalysts were clearly observed by SEM (Fig. 2). The surface of the CDMC3 catalyst prepared in the presence of the crown ether was relatively dispersive with a large surface area. For the CDMC3-T and CDMC3-B catalysts, their surfaces were disordered and multilayered, which indicated that the CDMC3 was even. However, the surface structures of the top and bottom portions of the DMC1 and DMC2 catalysts were found to be different, which indicated that these materials were not uniform, were consistent with those of the FTIR spectra.

\subsection{TGA-IR results}

TGA-IR spectra of the thermal decomposition products resulting from CDMC1 and DMC1 were recorded at different stages of the heating process to confirm the binding states of the $t$ - $\mathrm{BuOH}$ and crown ether ligands in these systems based on weight loss, and the results are shown in Table 3.

The decomposition profiles of DMC1 and CDMC1 were divided into three stages. The first of these stages occurred from 20 to about $120^{\circ} \mathrm{C}$. DMC1 and CDMC1 contained peaks at 3670, 2960, 1375 and $1059 \mathrm{~cm}^{-1}$, which were assigned to the $v_{0-\mathrm{H}}$, $v_{\mathrm{C}-\mathrm{H},} v_{\mathrm{C}-\mathrm{H}}$ and $v_{\mathrm{C}-\mathrm{O}}$ vibrations of $t$ - $\mathrm{BuOH}$ (Fig. 3). These results indicated that free $\mathrm{H}_{2} \mathrm{O}$ and $t$ - $\mathrm{BuOH}$ were being released during the first stage of the thermal decomposition process.

The second stage of the thermal decomposition process occurred from 120 to about $360{ }^{\circ} \mathrm{C}$ and corresponded to the loss of coordinated ligands (i.e., $t$ - $\mathrm{BuOH}$ and/or 18-crown-6). The presence of an alkene analogue was confirmed by FTIR analy- sis, which revealed peaks at 3080 and $1646 \mathrm{~cm}^{-1}$ corresponding to $v=\mathrm{C}-\mathrm{H}$ and $v_{\mathrm{C}=\mathrm{C}}$ at $123{ }^{\circ} \mathrm{C}$ above. Further evidence of an alkene was provided by an increase in the intensity of the characteristic peaks of the alkene above $326^{\circ} \mathrm{C}$, as shown in Fig. 3(a). The $t$-BuOH molecules present in the DMC1 and CDMC1 catalysts would undergo a dehydration reaction during the second stage to give 2-methylprop-1-ene. Figure 3 also revealed the formation of peaks at 1149 and $1021 \mathrm{~cm}^{-1}$, which were assigned to the asymmetrical and symmetrical stretching vibration of the ether bond of the crown ether.

The final stage in the thermal decomposition profiles of the DMC1 and CDMC1 catalysts occurred from 360 to $770{ }^{\circ} \mathrm{C}$. This stage was attributed to the decomposition of the cyano groups and the other organic ligands (i.e., $t$ - $\mathrm{BuOH}$ and 18-crown-6) attached to the active metallic center. The change in the stretching vibration of the $\mathrm{C} \equiv \mathrm{N}$ bond $\left(2278 \mathrm{~cm}^{-1}\right)$ in Fig. 3(a) (curve 4) implied that the cyano group was being converted to free cyanide during the final stage of the thermal decomposition process. At the same time, the characteristic adsorption peaks (3278 and $2180 \mathrm{~cm}^{-1}$ ) of an alkyne could also be seen. The decomposition residues of the DMC1 and CDMC1 catalysts were determined to be metallic oxides with weight ratios of $44.0 \%$ and $40.2 \%$, respectively. The compositions of these metal oxides were found to be in agreement with the results of the elemental analysis (CDMC1: $21.6 \% \mathrm{Zn}, 8.1 \%$ Co and $1.2 \% \mathrm{~K}$; DMC1: $25.1 \% \mathrm{Zn}, 8.6 \%$ Co and $1.4 \% \mathrm{~K}$ ).

As shown in Table 3, the metal oxides composition of CDMC1 (about 40.2\%) was less than that of DMC1 (about 44\%) because of the extra crown ether co-complexing agents. The decomposition products of the organic ligands (alkene and alkyne) could be observed by FTIR until the temperature reached $750{ }^{\circ} \mathrm{C}$, which indicated that these ligands were coor-

Table 3

Thermal decomposition stages of DMC1 and CDMC1.

\begin{tabular}{|c|c|c|c|c|c|}
\hline \multicolumn{2}{|l|}{ DMC1 } & \multicolumn{2}{|c|}{ CDMC1 } & \multirow{2}{*}{ Binding state } & \multirow{2}{*}{ Decomposition products } \\
\hline Temperature range $\left({ }^{\circ} \mathrm{C}\right)$ & Weight loss (\%) & Temperature range $\left({ }^{\circ} \mathrm{C}\right)$ & Weight loss (\%) & & \\
\hline $20-123$ & 2.4 & $20-110$ & 0.9 & Free & $\mathrm{H}_{2} \mathrm{O}$ and $t-\mathrm{BuOH}$ \\
\hline $123-357$ & 15.4 & $110-390$ & 17.8 & Coordinated & $t$-BuOH and alkene \\
\hline $357-775$ & 26.2 & $390-770$ & 20.4 & Coordinated or bonding & Alkene, cyanide and alkyne \\
\hline Ash & 44.0 & Ash & 40.2 & - & Metallic oxide \\
\hline
\end{tabular}



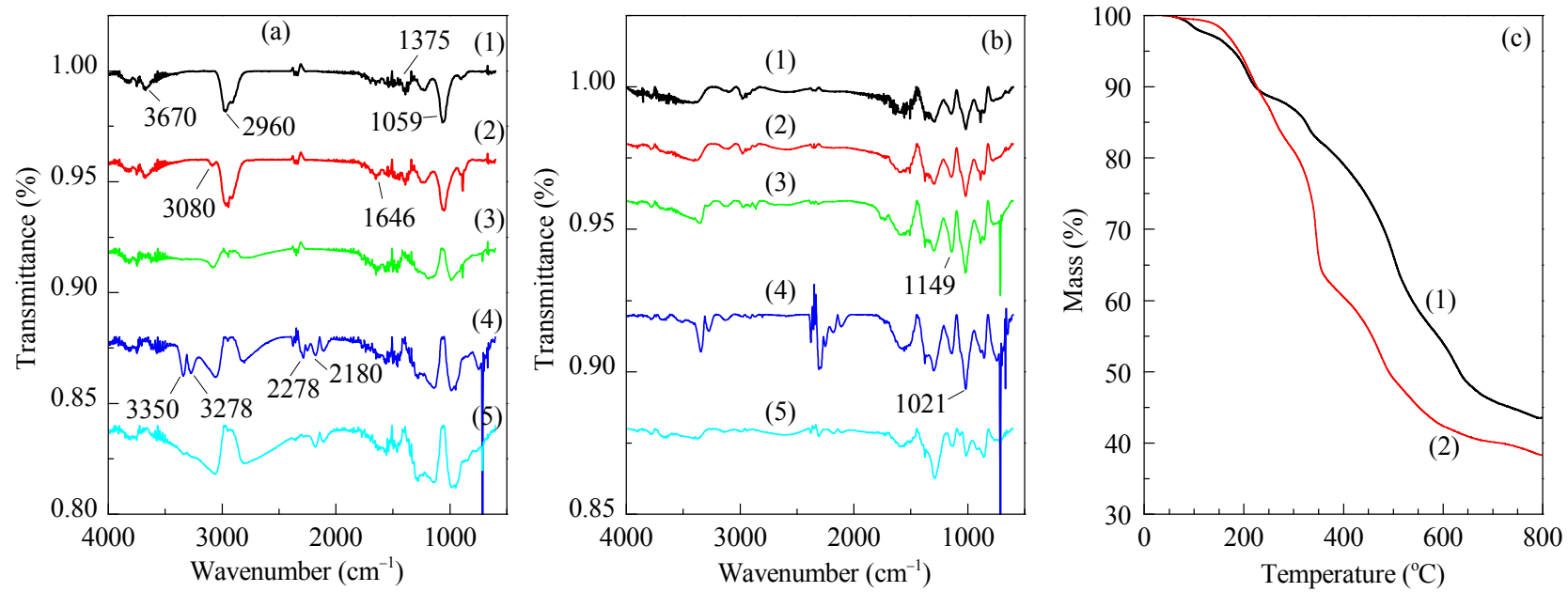

Fig. 3. FTIR spectra of gas mixture derived from thermal decomposition of DMC1 (a) and CDMC1 (b). (1) $94{ }^{\circ} \mathrm{C}$; (2) $206^{\circ} \mathrm{C}$; (3) $326^{\circ} \mathrm{C}$; (4) $500{ }^{\circ} \mathrm{C}$; (5) $625^{\circ} \mathrm{C}$. (c) TGA curves of DMC1 (1) and CDMC1 (2).

dinated to the metal center. After $290{ }^{\circ} \mathrm{C}$, the weight of the CDMC1 material diminished rapidly, whereas the weight loss from the DMC1 catalyst occurred at a much slower rate (Fig. 3 (c)). This difference in the weight loss profiles of the two catalysts could be attributed to the highly dispersive structure of CDMC1 compared with the more compact DMC1, as shown in Fig. 2. Furthermore, the loss of the cyano ligand from the CDMC1 material at $390^{\circ} \mathrm{C}$ occurred at a much higher temperature than that of the DMC1 catalyst $\left(357^{\circ} \mathrm{C}\right)$. This difference was attributed to an enhanced level of coordination from the 0 atom of the crown ether to the $\mathrm{Zn}$ ion in the CDMC1 catalyst, which would have led to the weakening of the bond between the cyano group and $\mathrm{Zn}$ ion, whilst strengthening the interaction between the cyano group and the Co metal center. The overall weight loss from the CDMC1 material (59.2\%) was higher than that of the DMC1 catalyst (56.0\%) between 20 and $770{ }^{\circ} \mathrm{C}$ because of the complexation of the crown ether.

\subsection{XRD analysis}

The XRD patterns of all of the catalysts are shown in Fig. 4. As expected, DMC0 catalyst (pure $\mathrm{Zn}_{3}\left[\mathrm{Co}(\mathrm{CN})_{6}\right]$ ), prepared in the absence of the ligand and excess $\mathrm{ZnCl}_{2}$ contained sharp

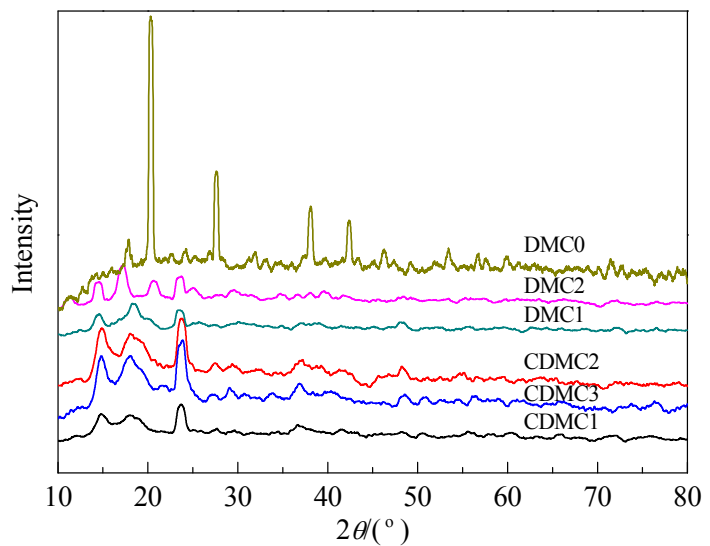

Fig. 4. XRD patterns of the CDMC and DMC catalysts. peaks with $d$-spacing values of $5.75,5.07,3.59,2.54$, and $2.28 \AA$, and exhibited a typical cubic lattice structure [36]. In general, the addition of an organic ligand such as $t$ - $\mathrm{BuOH}$ can disrupt the crystal structure and lead to a reduction in the crystallinity [32], which would be consistent with our XRD results. Regardless of whether the crown ether was added or not, other CDMC and DMC catalysts contained very broad and highly dispersed signals, which implied rather weak crystalline structures. For example, the XRD pattern among CDMC1 catalysts was the flattest of the all of the catalysts most likely because it contained the largest amount of crown ether. The signals at $12^{\circ}$ and $21^{\circ}$ in the DMC1 and DMC2 increased gradually, which suggested that the inclusion of multiple washing steps was leading to the generation of a new crystalline phase.

\subsection{The reproducibility of the CDMC catalysts}

CDMC2-1, CDMC2-2 and CDMC2-3 were prepared in the same manner using 18-crown-6 as the CDMC2. As shown in Table 4, the $\mathrm{Zn} / \mathrm{Co}$ molar ratios of these materials varied slightly from $1.77 \%$ to $1.86 \%$ for three independent experiments. The $\mathrm{C}$ and $\mathrm{N}$ contents of these catalysts were found to be almost equal because of the robust and highly reproducible nature of the processes involved in the preparation of these catalysts.

\subsection{Analysis of the polymerization results}

The coupling reactions of $\mathrm{CO}_{2}$ and epoxides can occur under mild conditions [38]. The coupling and copolymerization of $\mathrm{CO}_{2}$

Table 4

Elemental analyses of the CDMC catalysts.

\begin{tabular}{lccccc}
\hline Catalyst & $\begin{array}{c}\mathrm{K} \\
\text { (at\%) }\end{array}$ & $\begin{array}{c}\text { Zn/Co } \\
\text { molar ratio }\end{array}$ & $\begin{array}{c}\mathrm{C} \\
\text { (wt\%) }\end{array}$ & $\begin{array}{c}\mathrm{H} \\
\text { (wt\%) }\end{array}$ & $\begin{array}{c}\mathrm{N} \\
\text { (wt\%) }\end{array}$ \\
\hline CDMC2-1 & 1.26 & 1.80 & 29.84 & 3.277 & 13.41 \\
CDMC2-2 & 1.13 & 1.86 & 30.03 & 3.416 & 13.19 \\
CDMC2-3 & 1.14 & 1.77 & 30.09 & 3.359 & 13.06 \\
\hline
\end{tabular}

$\mathrm{K}$ content from the EDS; $\mathrm{C}, \mathrm{H}$ and $\mathrm{N}$ content from elemental analyses. 


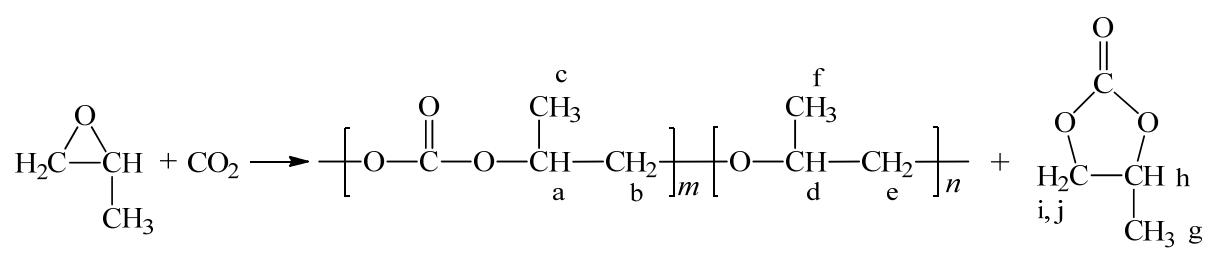

Scheme 1. Synthesis of PPC.

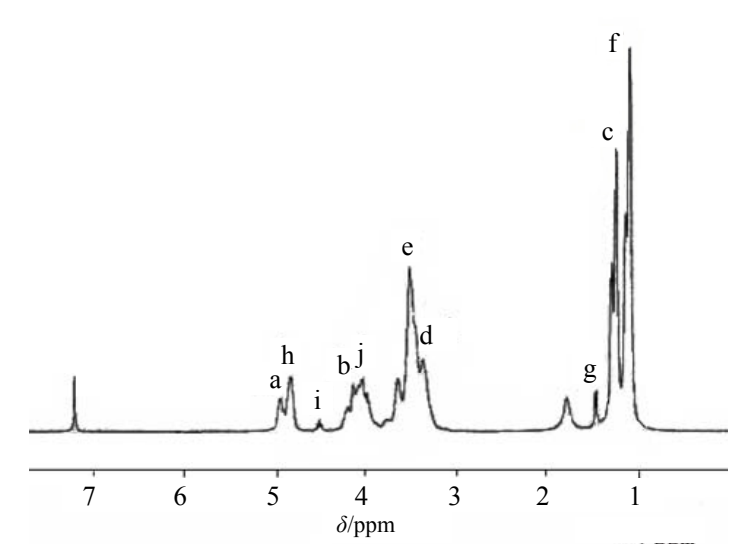

Fig. 5. ${ }^{1} \mathrm{H}$ NMR spectrum of the PPC copolymer.

and propylene oxide can occur simultaneously according to Scheme 1 . The amount of the copolymer and the coupling product can be counted by ${ }^{1} \mathrm{H}-\mathrm{NMR}$ as shown in Fig. 5 . The presence of $\mathrm{K}^{+}$in catalysts can have an adverse impact on their selectivity. 18-Crown- 6 was used to coordinate to the $\mathrm{K}^{+}$in an attempt to simply the procedure for the synthesis of uniform active heterogeneous Zn-Co DMC catalysts, which appear to provide the most promising combination of metals with high levels of activity and selectivity in copolymerization reactions. The results in Table 5 clearly show that the CDMC1 catalyst showed catalytic activity as high as $21889 \mathrm{~g} / \mathrm{g} \mathrm{Zn}$, which was much higher than those of the DMC1 and DMC2 catalysts (16300 and $16400 \mathrm{~g} / \mathrm{g} \mathrm{Zn}$, respectively). The polymer prepared in the presence of CDMC3 had a similar carbonate linkage content $(47.8 \%)$ to that of DMC2 $(48.3 \%)$, but much higher catalytic activity (32600 g/g Zn). The DMC1 catalyst prepared without 18-crown-6 and more washing steps, which was

Table 5

Results of the copolymerization catalyzed by various DMC catalysts ${ }^{\text {a }}$.

\begin{tabular}{lccccc}
\hline Catalyst & $\begin{array}{c}f_{\mathrm{CO}^{2}} \\
(\mathrm{~mol} \%)\end{array}$ & $\begin{array}{c}W_{\mathrm{PC}^{\mathrm{c}}} \\
(\mathrm{wt} \%)\end{array}$ & $\begin{array}{c}\text { Efficiency }^{\mathrm{d}} \\
\mathrm{g} / \mathrm{g} \mathrm{Zn} \mathrm{(g/g} \mathrm{cat.)}\end{array}$ & $M_{\mathrm{n}}$ & PDI \\
\hline CDMC1 & 40.6 & 3.3 & $21900(4728)$ & 31700 & 4.02 \\
CDMC2 & 42.0 & 2.6 & $27500(4683)$ & 32500 & 3.56 \\
CDMC3 & 47.8 & 1.5 & $32600(5122)$ & 38100 & 3.29 \\
DMC1 & 29.2 & 3.3 & $16300(4100)$ & 32000 & 4.10 \\
DMC2 & 48.3 & 2.4 & $16400(5073)$ & 38600 & 3.41 \\
DMC0 & - & - & 2.4 & - & - \\
\hline
\end{tabular}

a Copolymerization conditions: catalyst $7 \mathrm{mg}$, propylene oxide $30 \mathrm{~mL}$, $\mathrm{CO}_{2} 3.0 \mathrm{MPa} 16 \mathrm{~h}, 80^{\circ} \mathrm{C}$.

b Molar fraction of carbonate calculated based on the ${ }^{1} \mathrm{H}-\mathrm{NMR}$ peak area using the equation $f_{\mathrm{CO} 2}=\left(A_{5.0}+A_{4.2}-2 A_{4.6}\right) /\left(A_{5.0}+A_{4.2}-2 A_{4.6}+A_{3.5}\right)$.

c Weight fraction of the cyclic carbonate byproduct confirmed by referring to the ${ }^{1} \mathrm{H}-\mathrm{NMR}$ peak area using the equation $W_{\mathrm{PC}}=102 A_{1.5} /$ $\left[102\left(A_{5.0}+A_{4.2}-2 A_{4.6}+A_{1.5}\right)+58 A_{3.5}\right]$.

d Grams of polymer per gram of Zn and grams of polymer per gram of catalyst in parentheses. shown to contain $1.43 \% \mathrm{~K}$ by ICP analysis, was less active and selective than all of the CDMC catalysts and the DMC2 catalyst with seven washing steps. These results therefore imply that the free $\mathrm{K}^{+}$would be harmful to the copolymerization reactions of $\mathrm{CO}_{2}$ and epoxides. No $\mathrm{K}^{+}$was detected in the DMC2 catalyst. Both of the CDMC1 and CDMC2 materials were found to be much more active than DMC1. This result indicated that the coordination of the $\mathrm{K}^{+}$to 18 -crown- 6 was beneficial to the copolymerization reaction. DMC0, which was prepared without any organic ligands, had hardly any activity, which indicated that an active metallic center must be formed between a metal and some organic ligands to allow for the copolymerization of $\mathrm{CO}_{2}$ with epoxides.

\subsection{Possible mechanism}

Several well-known DMC catalysts have been used during the past two decades to catalyze the polymerization reactions of epoxides and the copolymerization reactions of $\mathrm{CO}_{2}$ with epoxides. Once the long induction time or activation stage is over, the polymerization reaction will proceed rapidly and reach termination in a short time. The final product of these reactions has two hydroxyl end groups, as confirmed by Zhang et al. [33]. It was envisaged that the polymerization reaction described in the current study proceeded in two stages, the slow activation stage and the rapid propagation stage, as depicted in Scheme 2. The reaction would begin with the coordination of $\mathrm{PO}$ to $\mathrm{Zn}$ and the subsequent nucleophilic ring-opening of the $\mathrm{PO}$ by a hydroxyl group coordinated to the active $\mathrm{Zn}$ center. Given that the amount of catalyst would be small relative to the monomer, the hydroxyl group coordinated to the active $\mathrm{Zn}$ center would not be regenerated, and the speed of the activation stage would therefore be restricted. However, during the propagation of the intermediate, the resulting $\mathrm{Zn}-\mathrm{OR}$ species could trigger a further polymerization reaction and be regenerated through a chain transfer, which would lead to the auto acceleration of the polymerization process. In addition, Lee et al. [39] found that the use of small linear aliphatic alcohols was preferred over bulky $t$ - $\mathrm{BuOH}$ in terms of shortening the induction period. It is possible that the reduction in steric hindrance resulting from the use of smaller alcohols would lead to an increase in the chain transfer, and therefore accelerate the activation period.

\section{Conclusions}

18-Crown- 6 has been used for the first time to coordinate $\mathrm{K}^{+}$ in an attempt to generate uniform and highly active Zn-Co DMC catalysts. Based on the FTIR and SEM results, it was clear that 


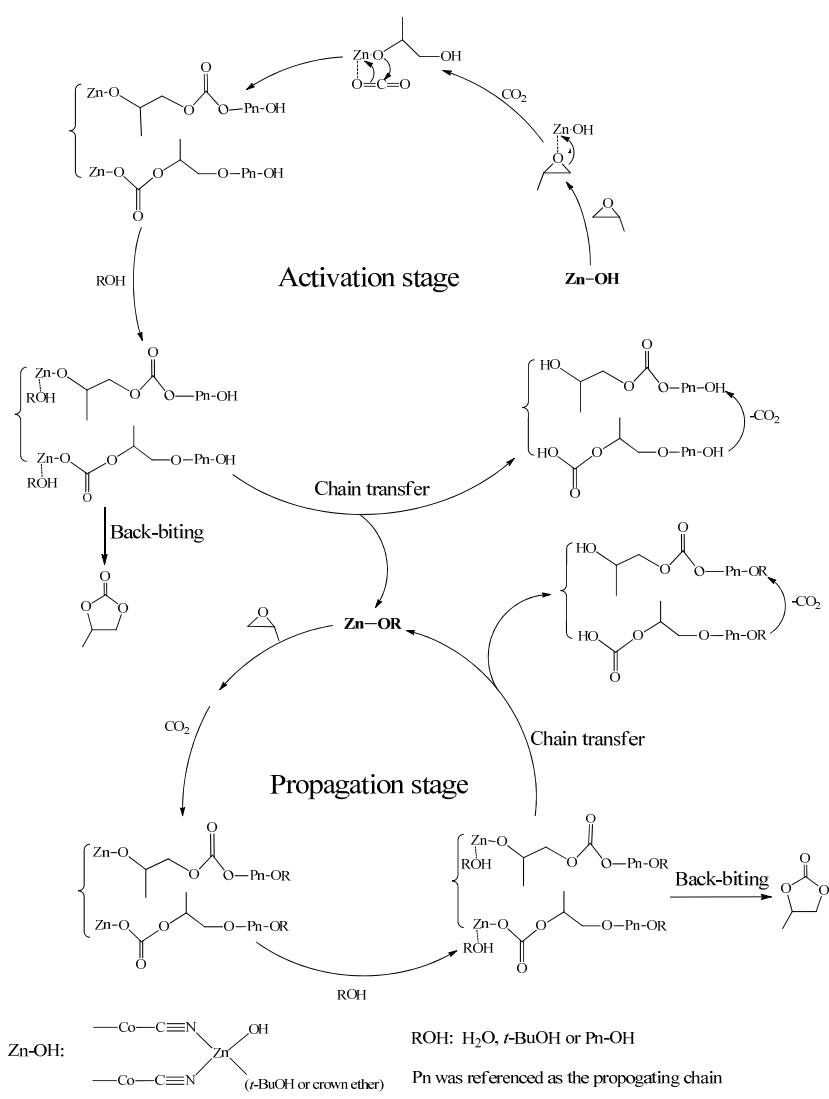

Scheme 2. Proposed mechanism of copolymerization.

the addition of crown ether had a significant impact on the surface morphologies of the catalysts, which became even and uniformly dispersed compared to the layered and compacted surfaces of the catalysts prepared in the absence of the crown ether. TGA-IR analysis showed that the active metallic center was formed from several metals coordinated to organic ligands ( $t$-BuOH and 18-crown-6). In spite of the large excess of $\mathrm{K}^{+}$, the crown ether complexing Zn-Co DMC catalyst prepared without the inclusion of extra washing steps (CDMC1) showed a high catalytic efficiency, which was similar to that the DMC2 catalyst prepared with multiple washings but in the absence of the crown ether. The catalytic efficiency of this material as high as $5122 \mathrm{~g} / \mathrm{g}$ catalyst ( $32600 \mathrm{~g} / \mathrm{g} \mathrm{Zn}$ ) was obtained in the presence of a $\mathrm{Zn}$-Co DMC with the addition of double the theoretical amount of the crown ether.

\section{References}

[1] Muelhaupt R. Macromol Chem Phys, 2013, 214: 159

[2] Nornberg B, Borchardt E, Luinstra G A, Fromm J. Eur Polym J, 2014, 51: 167

[3] Tang R Z, Chen T, Chen Y, Zhang Y Z, Wang G Y. Chin J Catal (唐荣 芝, 陈粀, 陈勇, 张元卓, 王公应. 催化学报), 2014, 35: 457

[4] Liu J, Wang A Q, Jing H W. Chin J Catal (刘靖, 王安琪, 景欢旺. 催 化学报), 2014, 35: 1669

[5] Kuran W, Listos T. Macromol Chem Phys, 1994, 195: 977

[6] Darensbourg D J, Holtcamp M W, Struck G E, Zimmer M S, Niezgoda S A, Rainey P, Robertson J B, Draper J D, Reibenspies J H. J Am Chem Soc, 1999, 121: 107

[7] Kim J S, Kim H, Yoon J, Heo K, Ree M. J Polym Sci Part A Polym Chem, 2005, 43: 4079

[8] Tang L, Xiao M, Xu Y, Wang S J, Meng Y Z. J Polym Res, 2013, 20: 190

[9] Meng Y Z, Du L C, Tiong S C, Zhu Q, Hay A S. J Polym Sci Part A Polym Chem, 2002, 40: 3579

[10] Olejnik R, Padelkova Z, Fridrichova A, Horacek M, Merna J, Ruzicka A. J Organomet Chem, 2014, 759: 1

[11] Pan X, Liu Z, Cheng R H, Jin D L, He X L, Liu B P. J Organomet Chem, 2014, 753: 63

[12] Dong Y L, Wang X H, Zhao X J, Wang F S. J Polym Sci Part A Polym Chem, 2012, 50: 362

[13] Wu W, Qin Y S, Wang X H, Wang F S. J Polym Sci Part A Polym Chem, 2013, 51: 493

[14] Anderson C E, Vagin S I, Hammann M, Zimmermann L, Rieger B. ChemCatChem, 2013, 5: 3269

[15] Bai D S, Wang X X, Song Y Y, Li B, Zhang L L, Yan P, Jing H W. Chin J Catal (柏东升, 王晓旋, 宋䒯莹, 李博, 张立龙, 问鹏, 景欢旺. 催

\section{Graphical Abstract}

Chin. J. Catal., 2015, 36: 1304-1311 doi: 10.1016/S1872-2067(15)60868-3

Preparation of crown ether complexing highly active double metal cyanide catalysts and copolymerization of $\mathrm{CO}_{2}$ and propylene oxide

Min Zhang*, Yong Yang, Liban Chen

Foshan University; Guangzhou Institute of Chemistry, Chinese Academy of Sciences; University of Chinese Academy of Sciences

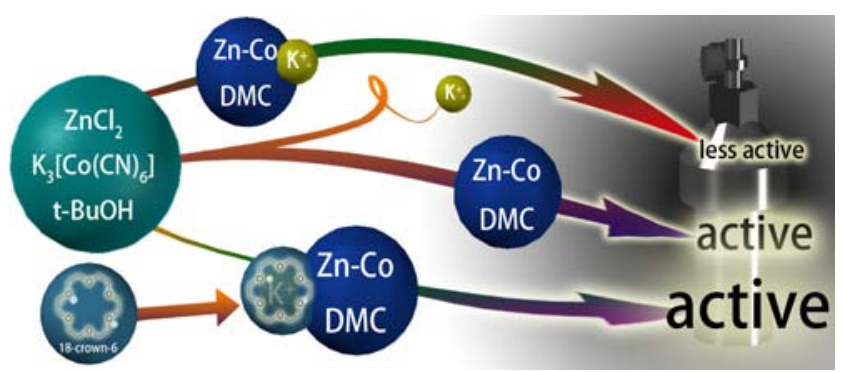

A new series of $\mathrm{Zn}$-Co double metal cyanide catalysts with $\mathrm{K}^{+}$fixed by 18-crown- 6 showed catalytic activity as high as $5122 \mathrm{~g} / \mathrm{g}$ for the copolymerization of $\mathrm{CO}_{2}$ with propylene. 
化学报), 2010, 31: 176

[16] Cheng M, Lobkovsky E B, Coates G W. J Am Chem Soc, 1998, 120 : 11018

[17] Zhang M, Chen L B, Liu B H, Yan Z R, Qin G, Li Z M. Polym Bull, 2001, 47: 255

[18] Rajendran N M, Haleel A, Reddy N D. Organometallics, 2014, 33: 217

[19] Wu G P, Xu P X, Lu X B, Zu Y P, Wei S H, Ren W M, Darensbourg D J. Macromolecules, 2013, 46: 2128

[20] Lu X B, Ren W M, Wu G P. Acc Chem Res, 2012, 45: 1721

[21] Darensbourg D J, Chung W C, Wilson S J. ACS Catal, 2013, 3: 3050

[22] Enthaler S. ACS Catal, 2013, 3: 150

[23] Tsai C Y, Huang B H, Hsiao M W, Lin C C, Ko B T. Inorg Chem, 2014, 53: 5109

[24] Nakano K, Kobayashi K, Ohkawara T, Imoto H, Nozaki K. J Am Chem Soc, 2013, 135: 8456

[25] Xie Y, Wang T T, Liu X H, Zou K, Deng W Q. Nat Commun, 2013, 4: 1960

[26] Oh H J, Ko Y S. J Ind Eng Chem, 2013, 19: 1939

[27] Huang Y J, Qi G R, Chen L S. Appl Catal A, 2003, 240: 263

[28] Chen S, Hua Z J, Fang Z, Qi G R. Polymer, 2004, 45: 6519
[29] Varghese J K, Park D S, Jeon J Y, Lee B Y. J Polym Sci Part A Polym Chem, 2013, 51: 4811

[30] Sebastian J, Srinivas D. Appl Catal A, 2014, 482: 300

[31] Zhou T C, Zou Z Q, Gan J Q, Chen L B, Zhang M. J Polym Res, 2011, 18: 2071

[32] Zhang X H, Hua Z J, Chen S, Liu F, Sun X K, Qi G R. Appl Catal A, 2007, 325: 91

[33] Zhang X H, Wei R J, Sun X K, Zhang J F, Du B Y, Fan Z Q, Qi G R. Polymer, 2011, 52: 5494

[34] Kim I, Yi M J, Lee K J, Park D W, Kim B U, Ha C S. Catal Today, 2006, 111: 292

[35] Ravindran A, Srivastavas R. Chin J Catal (催化学报), 2011, 32: 1597

[36] Kim I, Ahn J T, Ha C S, Yang C S, Park I. Polymer, 2003, 44: 3417

[37] Chen S, Zhang X H, Qi G R. Chin J Catal (陈上, 张兴宏, 戚国荣. 催 化学报), 2006, 27: 355

[38] Chang T, Gao X R, Bian L, Fu X Y, Yuan M X, Jing H W. Chin J Catal (常涛, 高晓芯, 边丽, 付西英, 袁明霞, 景欢旺. 催化学报), 2015, 36: 408

[39] Lee S H, Lee I K, Ha J Y, Jo J K, Park I, Ha C S, Suh H, Kim I. Ind Eng Chem Res, 2010, 49: 4107

\title{
冠醚络合高活性双金属氰化物制备及 $\mathrm{CO}_{2}$ 与环氧丙烷共聚
}

\author{
张 敏 ${ }^{\mathrm{a},{ }^{*}, \dagger}$, 杨 永 $^{\mathrm{b}, \mathrm{c}, \dagger}$, 陈立班 $^{\mathrm{b}}$ \\ a 佛山科学技术学院食品与园艺学院, 广东佛山528231

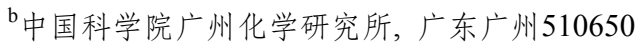 \\ ${ }^{\mathrm{c}}$ 中国科学院大学, 北京 100049
}

摘要: 首次在共沉淀过程中添加18-冠-6醚络合生成的钾离子得到了均一的高活性冠醚络合的锌-钴双金属催化剂, 并用红外光谱 (FTIR)、扫描电镜(SEM)、热重红外(TGA-IR)和X射线衍射(XRD)进行了表征. 元素分析发现K含量为 $1.2 \%$. FTIR表明未加冠醚络 合的双金属催化剂离心后上下部分呈现不同的络合状态,而冠醚络合的双金属催化剂仍保持均一. SEM表明冠醚络合的双金属 催化剂为均一松散的结构. 由于生成的钾离子被冠醚络合, 不影响聚合反应效果. TGA-IR表明冠醚不仅络合K离子, 还参与对金 属活性中心的络合. XRD表明此催化剂具有低的结晶度. 所制冠醚络合的锌-钴双金属催化剂能成功催化 $\mathrm{CO}_{2}$ 与环氧丙烷共聚, 其中CDMC3催化得到的共聚物碳酸酯含量为 $47.8 \%$, 副产物环状碳酸酯为 $1.5 \%$, 催化效率高达 $5122 \mathrm{~g} / \mathrm{g}$ 催化剂(32600 g/g Zn), 明 显优于不添加冠醚以同样工艺制备的DMC1 (共聚物碳酸酯含量 $29.2 \%$, 副产物环状碳酸酯 $3.3 \%$, 催化效率 $4100 \mathrm{~g} / \mathrm{g}$ 催化剂(16300 $\mathrm{g} / \mathrm{g} \mathrm{Zn}$ ). 与不添加冠醚 8 次洗涤离心得到的DMC2相当(共聚物碳酸酯含量 $48.3 \%$, 副产物环状碳酸酯含量 $2.4 \%$, 催化效率 $5073 \mathrm{~g} / \mathrm{g}$ 催化剂(16400 g/g Zn)). 基于此结果提出了两步的反应机理假设.

关键词：双金属氰化物；二氧化碳；环氧丙烷；共聚；冠醚

收稿日期: 2015-02-01. 接受日期: 2015-04-23. 出版日期: 2015-08-20.

*通讯联系人. 电话/传真: (0757)85505064; 电子信箱：zhangmin@gic.ac.cn

†张敏与杨永为共同第一作者.

基金来源：国家自然科学基金(20274053); 广东省自然科学基金(9151065004000005); 佛山市科技计划 (2014GA000425, 2014AG10007).

本文的英文电子版由Elsevier出版社在ScienceDirect上出版(http://www.sciencedirect.com/science/journal/18722067). 